\title{
Cinética de liofilização e modelagem matemática do leite asinino
}

\author{
Lyophilization kinetics and mathematical modeling of donkey milk \\ Cinética de liofilización y modelización matemática de la leche de burra
}

Recebido: 12/02/2021 | Revisado: 15/02/2021 | Aceito: 16/02/2021 | Publicado: 23/02/2021

Francisca Moisés de Sousa

ORCID: https://orcid.org/0000-0001-6152-480X

Universidade Federal de Campina Grande, Brasil

E-mail: fran_moyses@hotmail.com

Mário Eduardo Rangel Moreira Cavalcanti-Mata

ORCID: https://orcid.org/0000-0001-6919-207X

Universidade Federal de Campina Grande, Brasil

E-mail: mcavalcantimata@gmail.com

Maria Elita Martins Duarte

ORCID: https://orcid.org/0000-0002-3831-7201

Universidade Federal de Campina Grande, Brasil

E-mail: melitamd@gmail.com

Mylena Olga Pessoa Melo

ORCID: https://orcid.org/0000-0003-4007-3063

Universidade Federal de Campina Grande, Brasil

E-mail: mylenaopm@gmail.com

Manoel Tolentino Leite Filho

ORCID: https://orcid.org/0000-0002-3795-8816

Universidade Federal de Campina Grande, Brasil

E-mail: mtlfilho.1@gmail.com

Rebeca Morais Silva Santos

ORCID: https://orcid.org/0000-0003-0867-2795

Universidade Federal de Campina Grande, Brasil

E-mail: rebecamoraiscg@gmail.com

Michelly Daiane Araújo de Almeida

ORCID: https://orcid.org/0000-0002-0551-0048

Universidade Federal de Campina Grande, Brasil

E-mail: michellyalmeidamda@gmail.com

Anastácia Maria Mikaella Campos Nóbrega André

ORCID: https://orcid.org/0000-0001-5568-9894

Universidade Federal de Campina Grande, Brasil

E-mail: anastaciamikaella@gmail.com

Alexandre da Silva Lúcio

ORCID: https://orcid.org/0000-0002-3113-5317

Universidade Federal de Campina Grande, Brasil

E-mail: alexandre01lucio@gmail.com

Kamila de Lima Santos

ORCID: https://orcid.org/0000-0002-2605-9313

Universidade Federal de Campina Grande, Brasil

E-mail: kamiladelsantos@gmail.com

Jorge Jacó Alves Martins

ORCID: https://orcid.org/0000-0002-1074-2468

Universidade Federal de Campina Grande, Brasil

E-mail: jaco-m@hotmail.com

Larissa Monique de Sousa Rodrigues

ORCID: https://orcid.org/0000-0002-1134-6336

Universidade Federal de Campina Grande, Brasil

E-mail: larissamonique@gmail.com

\section{Resumo}

O interesse no leite de asinino vem destacando-se devido a estudos relacionados às suas características benéficas, apresenta semelhanças na palatabilidade e composição quando comparado ao leite materno. O leite dessa espécie demonstrou ser pobre em proteínas e gorduras, e rico em lactose, além de apresentar propriedades antimicrobianas, tornando-o um alimento ideal para suplemento humano e principalmente como alimento alternativo para crianças com alergia à proteína do leite de vaca. Diante disso, o objetivo deste trabalho foi estudar a cinética de liofilização para o leite asinino submetido a diferentes temperaturas de congelamento $\left(-20,-60,-100\right.$ e $\left.-140^{\circ} \mathrm{C}\right)$, bem como determinar a difusividade efetiva e as propriedades termodinâmicas. Os dados experimentais foram submetidos a analises dos 
modelos de secagem teórico, semiteórico, semiempíricos e empírico, e os parâmetros $\mathrm{R}^{2}, \mathrm{R}_{\mathrm{a}}^{2}, \mathrm{P}(\%)$, $\mathrm{SE}$ e DQM foram determinados. Dentre os modelos de secagem estudados o Modelo de Cavalcanti-Mata modificado, foi o que apresentou melhor ajuste aos dados experimentais. Nos modelos de Fick modificado, Cavalcanti-Mata modificado, Lewis modificado e Page modificado, a difusividade efetiva decresceu com a diminuição da temperatura de congelamento e em consequência disto, constata-se que a entalpia e a entropia diminuiu a medida que a temperatura de congelamento foi baixando e a energia livre de Gibbs demonstrou que o processo não é espontâneo.

Palavras-chave: Cinética de secagem; Leite de jumenta; Difusividade efetiva; Propriedades termodinâmicas.

\begin{abstract}
He interest in donkey milk has been highlighted due to studies related to its beneficial characteristics, it has similarities in palatability and composition when compared to breast milk. Milk of this species has been shown to be low in protein and fat, and rich in lactose, in addition to having antimicrobial properties, making it an ideal food for human supplement and mainly as an alternative food for children with allergy to cow's milk protein. Therefore, the objective of this work was to study the lyophilization kinetics for donkey milk submitted to different freezing temperatures $(-20,-60,-100$ and $-140^{\circ} \mathrm{C}$ ), as well as to determine the effective diffusivity and thermodynamic properties. The experimental data were subjected to analysis of the theoretical, semi-theoretical, semi-empirical and empirical drying models, and the parameters R2, Ra2, P (\%), SE and DQM were determined. Among the drying models studied, the modified CavalcantiMata model was the one that presented the best adjustment to the experimental data. In the models of Fick modified, Cavalcanti-Mata modified, Lewis modified and Page modified, the effective diffusivity decreased with the decrease of the freezing temperature and as a result of this, it appears that enthalpy and entropy decreased as the freezing temperature dropped and Gibbs' free energy demonstrated that the process is not spontaneous.
\end{abstract}

Keywords: Drying kinetics; Donkey milk; Effective diffusivity; Thermodynamic properties.

\begin{abstract}
Resumen
El interés por la leche de burra se ha destacado debido a estudios relacionados con sus características beneficiosas, tiene similitudes en palatabilidad y composición en comparación con la leche materna. Se ha demostrado que la leche de esta especie es baja en proteínas y grasas, y rica en lactosa, además de tener propiedades antimicrobianas, lo que la convierte en un alimento ideal para el complemento humano y principalmente como alimento alternativo para niños con alergia a la proteína de la leche de vaca. Por tanto, el objetivo de este trabajo fue estudiar la cinética de liofilización de la leche de burra sometida a diferentes temperaturas de congelación $\left(-20,-60,-100\right.$ y $\left.-140^{\circ} \mathrm{C}\right)$, así como determinar la difusividad efectiva y propiedades termodinámicas.. Los datos experimentales fueron sometidos a análisis de los modelos de secado teórico, semisoteórico, semi-empírico y empírico, y se determinaron los parámetros R2, Ra2, P (\%), SE y DQM. Entre los modelos de secado estudiados, el modelo Cavalcanti-Mata modificado fue el que presentó el mejor ajuste a los datos experimentales. En los modelos de Fick modificado, Cavalcanti-Mata modificado, Lewis modificado y Page modificado, la difusividad efectiva disminuyó con la disminución de la temperatura de congelación y como resultado, parece que la entalpía y la entropía disminuyeron a medida que descendió la temperatura de congelación y la energía libre de Gibbs demostró que el proceso no es espontáneo.
\end{abstract}

Palabras clave: Cinética de secado; Leche burra; Difusividad efectiva; Propiedades termodinâmicas.

\title{
1. Introdução
}

A espécie asinina, Equus asinus, assim como os cavalos e as zebras pertencem a uma mesma família de animais denominada por Equidae (Machado, 2015). A população mundial de asininos é de aproximadamente 45 milhões e o número estimado de animais no Brasil é de 927.000 cabeças (FAO, 2016).

Segundo Altomonte et al. (2019) os jumentos desempenham um papel importante como animais de trabalho em muitas economias rurais, atividades recreativas, para a produção de carne, bem como para obter gelatina utilizada em medicamentos tradicionais asiáticos, produção de leite destinado à nutrição humana e cosméticos. Mas, com a industrialização e a mecanização na agricultura, tem-se observado uma progressiva tendência para a substituição destes animais associados ao transporte e ao trabalho, havendo um abandono da exploração e utilização destes animais (Machado, 2015).

Apesar do tamanho da população de asininos no Brasil e sua importância socioeconômica e cultural, ainda não existe definição clara de sistemas de produção voltados para a exploração racional da espécie, o que desfavorece a organização da cadeia produtiva do leite de jumenta e seus derivados (Rangel et al., 2015). Contudo, as jumentas são boas produtoras de leite, podendo produzir o equivalente a 2,8 - $3 \%$ do seu PV/dia e a vendagem deste produto, de forma racional, pode simbolizar um acréscimo na receita dos haras e de pequenos produtores rurais brasileiros (Santos, 2017). 
Ultimamente o interesse no leite de jumenta vem destacando-se devido a estudos relacionados às características benéficas, principalmente no campo científico da nutrição humana. Segundo Silva (2015) a ingestão do leite de jumenta tem crescido devido a sua alta tolerabilidade, como alimento alternativo para crianças com alergia à proteína do leite de vaca, além de apresentar semelhanças na palatabilidade como na sua composição quando comparado ao leite materno. De um modo geral, o leite dessa espécie demonstrou ser pobre em proteínas e gorduras, e rico em lactose, demostrando mais semelhança ao leite de égua e humano do que o de outros mamíferos, além de apresentar propriedades antimicrobianas, tornando-o um alimento ideal para suplemento humano (Massouras, Triantaphyllopoulos \& Theodossiou, 2017).

Diante de tal semelhança e sabendo-se da importância do leite materno para o desenvolvimento e sistema imunológico do recém-nascido, pesquisadores buscam alternativas seguras e eficientes para diminuir as consequências que o desmame precoce pode causar à saúde da criança. Como alternativa para crianças alérgicas que não são amamentadas, existem fórmulas comercialmente disponíveis que incluem hidrolisados de proteínas do leite de vaca, fórmulas de aminoácidos e bebidas de soja, porém alguns produtos mantêm o potencial alergênico, precisando de aprimoramento nutricional ou apresentam pouca palatabilidade (Altomonte et al, 2019). Mas segundo SBP (2016) a alergia a proteína do leite de vaca é a causa mais comum de alergia alimentar em crianças e adolescentes. Diante disto, ensaios clínicos têm demonstrado que as fórmulas de leite infantil, as quais são em sua maioria à base de leite de vaca, são menos adaptáveis à dieta de pacientes afetados pela alergia à proteína do leite de vaca (CMPA) do que o leite de jumenta (Iacono et al., 1992; Caroccio et al., 2000; Cosentino et al., 2012; Cosentino et al., 2015).

De acordo com Trinchese et al. (2015) o leite de asinino apresenta o efeito hipolipêmico capaz de influenciar a homeostase metabólica e o estado inflamatório, modulando a função mitocondrial e a composição microbiana intestinal. Deste modo, também pode ser de grande relevância para os adultos, pois por apresentar baixo teor de gordura o consumo do leite de jumenta, bem como os seus derivados, pode ser valioso na dieta de pessoas idosas, podendo ser útil na prevenção de aterosclerose e também pela sua capacidade em aumentar a resposta imunológica em humanos (Salimei \& Fantuz, 2012).

Tendo em vista que o leite é um alimento altamente perecível e precisa ser armazenado de forma segura, um processo alternativo para a conservação de alimentos é a liofilização. Quando aplicada a tecnologia de liofilização, a composição do leite e o seu valor nutricional mantém-se similares à do leite antes do tratamento, os produtos liofilizados quando reconstituídos retornam às suas propriedades originais como nenhum outro produto desidratado, provocando poucas alterações no que diz respeito às características sensoriais, como o sabor, odor, cor e textura do produto (Martins et al., 2011).

Mesmo diante de todas essas qualidades citadas acima, na literatura ainda são poucos os trabalhos que incluem uma descrição completa de aspectos nutricionais, físico-químicos, físicos e variabilidade composicional sobre o leite de origem asinina em comparação com outras espécies leiteiras. Portando, o presente trabalho é uma contribuição para a literatura sobre o leite asinino, com o objetivo de elaborar um produto em pó obtido pelo processo de liofilização e estudar a cinética de secagem submetidos a diferentes temperaturas de congelamento $\left(-20,-60,-100\right.$ e $\left.-140^{\circ} \mathrm{C}\right)$, introduzindo novos conceitos propostos por Cavalcanti-Mata (2018) a partir do modelo de Fick, dando novo significado as equações propostas por Page, Lewis e Cavalcanti Mata, bem como determinar a difusividade efetiva, energia de ativação do produto e as propriedades termodinâmicas (entalpia, entropia e energia livre de Gibbs).

\section{Metodologia}

Nesta pesquisa foi utilizado o leite proveniente de uma pequena criação de 8 jumentas da raça Nordestino, situada no agreste, na cidade de Bezerros- PE, adquirido através de doação. Logo após a ordenha, o leite foi congelado $-5^{\circ} \mathrm{C}$ em garrafas e transportado em caixa térmica até o Laboratório de Tecnologia do Frio pertencente à Unidade Acadêmica de Engenharia de Alimentos (UAEAli), localizado na Universidade Federal de Campina Grande, Campus Campina Grande, PB. Trata-se de uma 
pesquisa quantitativa por se tratar da coleta de dados numéricos através de medições de grandezas em suas respectivas unidades, utilizando-se metodologias específicas (Pereira et al., 2018).

No laboratório o leite asinino foi descongelado sob-refrigeração $\left(0\right.$ a $\left.4^{\circ} \mathrm{C}\right)$ e em seguida pasteurizado por 30 minutos a $65^{\circ} \mathrm{C}$ em banho-maria, depois embalado, congelados às temperaturas de $-20^{\circ} \mathrm{C},-60,-100 \mathrm{e}-140^{\circ} \mathrm{C}$ e armazenados em freezer as mesmas temperaturas.

As amostras para o congelamento às temperaturas de $-20,-60,-100$ e $-140{ }^{\circ} \mathrm{C}$ foram realizadas em triplicata sendo colocadas em recipientes de silicone na forma de placa plana de $10 \mathrm{~mm}$ de espessura, após o congelamento foram colocadas dentro de um tubo de vidro com capacidade de $500 \mathrm{~mL}$ e acoplado à válvula (manifolds) do Liofilizador. A cinética de secagem do leite asinino foi realizada usando-se o Liofilizador Terroni, modelo de Bancada Série LS 6000 A. Durante a secagem foram monitorados o tempo de liofilização e o teor de água do produto, portanto, para que não haja perda de vácuo dentro do tubo que contém a amostra, foi montado um sistema, com registros acoplados ao tubo, que permitem interromper o vácuo e retirar o tubo. A válvula (manifolds) foi fechada e as amostras retiradas para pesagem em balança semianalítica em intervalos de 30 minutos nas $2 \mathrm{~h} 30 \mathrm{~min}$ iniciais do processo, de 60 minutos durante 6 horas e de 2 horas até $\mathrm{o}$ a amostra atingir peso constante, finalizandose o processo. A partir dos dados de variação do teor de água com o tempo de liofilização, foi determinada a cinética de liofilização (Equação 1).

$$
\mathrm{RX}=\frac{\mathrm{X}_{\mathrm{t}}-\mathrm{X}_{\mathrm{e}}}{\mathrm{X}_{0}-\mathrm{X}_{\mathrm{e}}}
$$

em que:

$\mathrm{RX}$ = razão de teor de água, adimensional;

$\mathrm{X}_{\mathrm{e}}=$ teor de água de equilíbrio à pressão de 0,14 mmbar, base seca, decimal;

$\mathrm{X}=$ teor de água a cada tempo à pressão de $0,14 \mathrm{mmbar}$, base seca, decimal;

$\mathrm{X}_{\mathrm{i}}=$ teor de água inicial à pressão de 0,14 mmbar em base seca, decimal;

Considerando-se que a sublimação se deu de forma análoga ao processo de secagem em taxa decrescente, como no processo de secagem convectiva o modelo para o estudo da cinética de liofilização foi baseado na segunda Lei de Fick e nas soluções analíticas da equação de difusão, apresentada por Crank (1975) com algumas alterações. Assim, a lei de Fick, Equação (2) de balanço de massa de água do interior do produto foi modificada considerando-se a difusividade efetiva (Def) como a difusividade de sublimação (Ks), tem-se então que a Equação (2) é transformada na Equação (3):

$$
\frac{\partial \mathrm{X}}{\partial \mathrm{t}}=\nabla\left(\mathrm{D}_{\mathrm{ef}} \nabla \mathrm{X}\right)
$$

em que:

$X=$ teor de água do produto em base seca, decimal;

$t=$ tempo de secagem, segundos;

$D_{e f}=$ difusividade de massa efetiva, $\mathrm{m}^{2} \cdot \mathrm{s}^{-1}$

$$
\frac{\partial \mathrm{X}}{\partial \mathrm{t}}=\nabla\left(\mathrm{D}_{s} \nabla \mathrm{X}\right)
$$

Aplicando a Lei de Fick modificada para predizer a velocidade do movimento da água por sublimação no processo de liofilização, temos a equação 4 : 


$$
\frac{\partial \mathrm{X}}{\partial \mathrm{t}}=\mathrm{D}_{\mathrm{s}}\left(\frac{\partial^{2} \mathrm{X}}{\partial \mathrm{X}^{2}}+\frac{\mathrm{q}}{\psi} \frac{\partial \mathrm{X}}{\partial \mathrm{x}}\right)
$$

Para legitimar esse modelo, se devem considerar as seguintes hipóteses:

- Sublimação constante;

- Geometria como uma placa plana infinita de espessura L;

- O teor de água interna é unidirecional;

- Encolhimento do produto desprezado.

A Equação 5 tem várias soluções para geometrias diferenciadas: Sendo para placa plana $(\mathrm{q}=0)$, cilíndrica $(\mathrm{q}=1)$ e esférica $(q=2)$; considerando apenas o fluxo na direção $X$ da espessura e com as seguintes condições inicial e de contorno: Para placa plana: $\psi=\mathrm{L}$

$$
\frac{\bar{X}_{\mathrm{s}}-\mathrm{X}_{\mathrm{es}}}{\mathrm{X}_{\mathrm{si}}-\mathrm{X}_{\mathrm{es}}}=\frac{8}{\pi^{2}} \sum_{\mathrm{n}=0}^{\infty} \frac{1}{(2 \mathrm{n}+1)^{2}} \cdot \exp \left(-(2 \mathrm{n}+1)^{2} \cdot \frac{\pi^{2} \mathrm{D}_{\mathrm{s}}}{4 \mathrm{~L}^{2}} \cdot \mathrm{t}\right)
$$

em que:

$\frac{X-X_{e}}{X_{\mathrm{i}}-X_{\mathrm{e}}}=$ razão de teor de água no processo de sublimação, adimensional;

$\mathrm{X}=$ teor de água submetida a pressão de 0.14 mmbar a cada tempo, decimal;

$\mathrm{X}_{\mathrm{i}}=$ teor de água inicial submetida a pressão de $0.14 \mathrm{mmbar}$, decimal;

$\mathrm{X}_{\mathrm{e}}=$ teor de água de equilíbrio a pressão de $0.14 \mathrm{mmbar}$, decimal;

$\mathrm{D}_{\mathrm{s}}=$ difusividade efetiva por sublimação a $0,14 \mathrm{mmbar}, \mathrm{m}^{2} \mathrm{~s}^{-1}, \mathrm{~mm}^{2} \mathrm{~s}^{-1}$;

$\mathrm{L}=$ comprimento característico (meia espessura da amostra), $\mathrm{mm}$;

$\mathrm{t}=$ tempo, minutos.

O estudo do mecanismo que conduz o processo de secagem é realizado pela análise de dados experimentais usando modelos matemáticos. Em geral, os modelos empíricos são uma expressão da lei de resfriamento de Newton, aplicada à transferência de massa durante a secagem e assumem que as condições sejam isotérmicas e que a transferência de água se restrinja à superfície do produto (Oliveira, 2016).

Os modelos exponenciais destacam-se entre os modelos semiteóricos, semiempíricos e empíricos. No presente estudo para predizer a cinética de liofilização foram utilizados os modelos matemáticos em similaridade ao de secagem convectiva, com base no modelo matemático da difusão líquida para placa plana infinita, cujas equações correspondentes estão descritas na Tabela 1. 
Tabela 1. Modelos matemáticos empregados na cinética de liofilização do leite de jumenta.
Modelo Teórico
Equação

Fick ( $1^{\circ}$ termo da série)

$$
\frac{\bar{X}_{s}-X_{e s}}{X_{s i}-X_{e s}}=\frac{8}{\pi^{2}} \sum_{n=0}^{6} \frac{1}{(2 n+1)^{2}} \cdot \exp \left(-(2 n+1)^{2} \cdot \frac{\pi^{2} D_{s}}{4 L^{2}} \cdot t\right)
$$

Modelo Semiteórico

Equação

Cavalcanti-Mata modificada $\quad \mathrm{RX}=\mathrm{a}_{1} \cdot \exp \left(-\frac{\pi^{2} \mathrm{D}_{\mathrm{s}}}{4 \mathrm{~L}^{2}} \cdot \mathrm{t}^{\mathrm{N}_{1}}\right)+\mathrm{a}_{2} \cdot \exp \left(-\frac{9 \cdot \pi^{2} \cdot \mathrm{D}_{\mathrm{s}}}{4 \mathrm{~L}^{2}} \cdot \mathrm{t}^{\mathrm{N}_{2}}\right)$

Modelo Semiempírico

Lewis modificada

Page modificada
Equação

$$
\mathrm{RX}=\exp \left(-\frac{\pi^{2} \mathrm{D}_{\mathrm{s}}}{4 \mathrm{~L}^{2}} \cdot \mathrm{t}\right)
$$$$
\mathrm{RX}=\exp \left(-\frac{\pi^{2} \mathrm{D}_{\mathrm{s}}}{4 \mathrm{~L}^{2}} \cdot \mathrm{t}^{\mathrm{n}}\right)
$$

Modelo empírico

Midilli et al.

$$
\mathrm{RX}=\mathrm{a} \cdot \exp \left(-\mathrm{k}_{\mathrm{s}} \cdot \mathrm{t}^{\mathrm{n}}\right)+\mathrm{b} \cdot \mathrm{t}
$$

$\mathrm{t}$ = tempo em minutos; a1, a2, a3, a, b e n = são constantes do modelo. Fonte: Autores (2021).

Os parâmetros dos modelos foram obtidos por análise de regressão não linear empregando-se o método numérico Quasi-Newton para todos os modelos, por meio do Software Statistica 7.0. Como critério de seleção para estabelecer o modelo que melhor representará o processo de secagem por sublimação, foram utilizados o coeficiente de determinação $\left(\mathrm{R}^{2}\right)$, o coeficiente de determinação ajustado $\left(\mathrm{R}^{2}\right.$ a) calculado pela Equação 11, o erro médio relativo $(\mathrm{P})$ calculado conforme Equação 12, o desvio-padrão da estimativa (SE) conforme Equação 13 e o desvio quadrático médio (DQM), calculado pela Equação 14.

$$
\begin{gathered}
\mathrm{R}_{\mathrm{a}}^{2}=1-\left(\frac{\mathrm{n}-1}{\mathrm{n}-(\mathrm{p}+1)}\right) \cdot\left(1-\mathrm{R}^{2}\right) \\
\mathrm{P}=\frac{100}{\mathrm{n}} \sum_{\mathrm{i}=1}^{\mathrm{n}}\left|\mathrm{TC}_{\text {exp }}-\mathrm{TC}_{\text {pred }}\right| / \mathrm{TC}_{\mathrm{pred}} \\
\mathrm{SE}=\sqrt{\frac{\left(\sum_{\mathrm{i}=1}^{\mathrm{n}}\left(\mathrm{TC}_{\text {exp }}-\mathrm{TC}_{\mathrm{pred}}\right)^{2}\right.}{\mathrm{GLR}}} \\
\mathrm{DQM}=\sqrt{\left.\frac{1}{\mathrm{~N}} \sum_{\mathrm{i}=1}^{\mathrm{N}} \mathrm{TC}_{\text {exp }}-\mathrm{TC}_{\mathrm{pred}}\right)^{2}}
\end{gathered}
$$

em que:

$\mathrm{R}_{\mathrm{a}}^{2}=$ coeficiente de determinação ajustado;

$\mathrm{R}^{2}=$ coeficiente de determinação;

$\mathrm{n}$ = número de dados experimentais;

$\mathrm{p}$ = número de parâmetros determinados pelo modelo; 
DQM = desvio quadratico médio;

$R X_{\text {exp }}=$ Razão do teor de água obtida experimentalmente;

$R X_{\text {pre }}=$ Razão do teor de água predita pelo modelo matemático;

$\mathrm{P}=$ erro médio relativo;

$\mathrm{SE}=$ erro padrão;

GLR = grau de liberdade do resíduo.

Com base na determinação da difusividade efetiva de sublimação determina-se e a energia de ativação ( $\left.\mathrm{E}_{\mathrm{a}}\right)$ do processo, por meio da equação de Arrhenius, Equação 15 (Horn et al., 2010).

$$
\alpha=D_{0} \exp \left(\frac{E_{a}}{8,314 \mathrm{~T}}\right)
$$

em que,

$\mathrm{T}$ - temperatura em Kelvin;

$\mathrm{D}_{0}$ - constante;

$\mathrm{R}$ - constante universal dos gases, $8,314 \mathrm{~J} \mathrm{~mol}^{-1} \mathrm{~K}^{-1}$;

$\mathrm{E}_{\mathrm{a}}$ - energia de ativação $\left(\mathrm{J} \mathrm{mol}^{-1}\right)$.

Com a obtenção da energia de ativação e do parâmetro $\mathrm{D}_{0}$ determinam-se os cálculos das propriedades termodinâmicas do processo, tais como: entalpia, entropia e energia livre de Gibbs. Segundo Jideani e Mpotokwana (2009), esses três parâmetros podem ser determinados a partir, respectivamente, das Equações: (16), (17) e (18):

$$
\begin{gathered}
\Delta \mathrm{H}=\mathrm{E}_{\mathrm{a}}-\mathrm{RT} \\
\Delta \mathrm{S}=\mathrm{R}\left[\ln \left(\mathrm{D}_{0}\right)-\ln \left(\frac{\mathrm{k}_{\mathrm{b}}}{\mathrm{k}_{\mathrm{p}}}\right)-\ln (\mathrm{T})\right] \\
\Delta \mathrm{G}=\Delta \mathrm{H}-\mathrm{T} \Delta \mathrm{S}
\end{gathered}
$$

em que:

$\Delta \mathrm{H}$ - entalpia, $\mathrm{J} \mathrm{mol}^{-1}$;

$\Delta \mathrm{S}$ - entropia, $\mathrm{J} \mathrm{mol}^{-1} \mathrm{~K}^{-1}$;

$\Delta \mathrm{G}$ - energia livre de Gibbs, $\mathrm{J}^{\mathrm{mol}^{-1}} \mathrm{~K}^{-1}$;

$\mathrm{k}_{\mathrm{b}}$ - constante de Boltzmann, 1,38.10-23 $\mathrm{J} \mathrm{K}^{-1}$;

$\mathrm{kp}$ - constante de Planck, 6,626.10 $10^{-34} \mathrm{~J} \mathrm{~s}^{-1}$.

\section{Resultados e Discussão}

Na Figura 1 estão os dados experimentais da cinética de secagem por liofilização do leite asinino para as temperaturas de congelamento de $-20,-60,-100$ e $-140^{\circ} \mathrm{C}$, nas quais as curvas são uma relação entre a razão do teor de água (adimensional) e tempo (minutos). 
Figura 1. Dados experimentais da secagem de liofilização para as temperaturas de congelamento de $-20,-60,-100$ e $-140^{\circ} \mathrm{C}$.

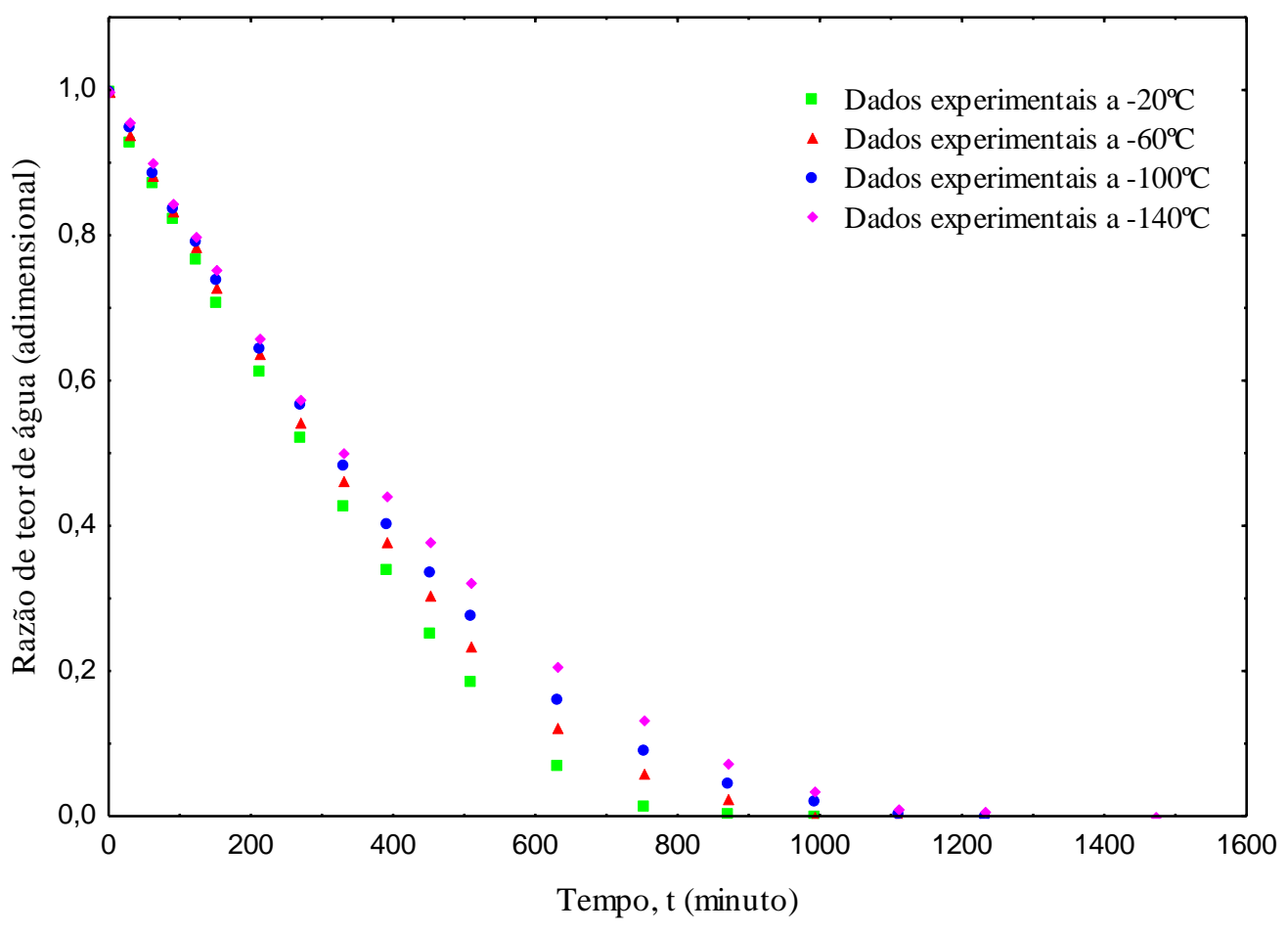

Fonte: Autores (2021).

Verifica-se que as curvas de secagem por liofilização têm comportamento semelhante com relação às taxas de remoção de água, porém os tempos médios para completar o processo de secagem são diferentes e foram de 990, 1110, 1230, e 1470 minutos, respectivamente às temperaturas de $-20,-60,-100$ e $-140^{\circ} \mathrm{C}$ (Figura 1).

Com relação às temperaturas de congelamento no processo de liofilização, nota-se uma influência das temperaturas nas curvas de secagem e observando-se uma maior perda de água quando o leite de asinino é liofilizado com a temperatura de $20{ }^{\circ} \mathrm{C}$, demostrando que quanto menor for a temperatura de congelamento, mais lento ocorrerá o processo de remoção de água e consequentemente um aumento do tempo de secagem. Oliveira (2016) estudando as curvas de cinética de liofilização da polpa de maracujá do mato in natura pré-congeladas nas temperaturas de $-25^{\circ} \mathrm{C},-60^{\circ} \mathrm{C},-76^{\circ} \mathrm{C}$ e $-170^{\circ} \mathrm{C}$, relatou comportamento semelhante de perda de água. De acordo com Orrego Alzate (2008 apud Oliveira, 2016), este comportamento justifica-se devido ao fato de as menores velocidades de congelação favorecerem a formação de cristais de gelo de maior tamanho e consequentemente maior porosidade, o que facilita a remoção da água dos materiais por liofilização.

Na Figura 2 encontram-se os dados experimentais da secagem por liofilização do leite asinino e os calculados com 6 termos da série, e na Tabela 2 estão os valores da difusividade de sublimação efetiva (Ds) determinada pela equação de Fick modificada indo do $1^{\circ}$ termo da série até o $6^{\circ}$ termos da série, no qual os valores determinados pela referida equação para seis termos, variaram entre $3,85 \cdot 10^{-10}$ a $2,83 \cdot 10^{-10} \mathrm{~m}^{2} \mathrm{~s}^{-1}$. 
Figura 2. Dados experimentais e calculados da secagem de liofilização do leite asinino nas temperaturas de congelamento -20 a $-140^{\circ} \mathrm{C}$ utilizando-se o Modelo de Fick com 6 termos da série.

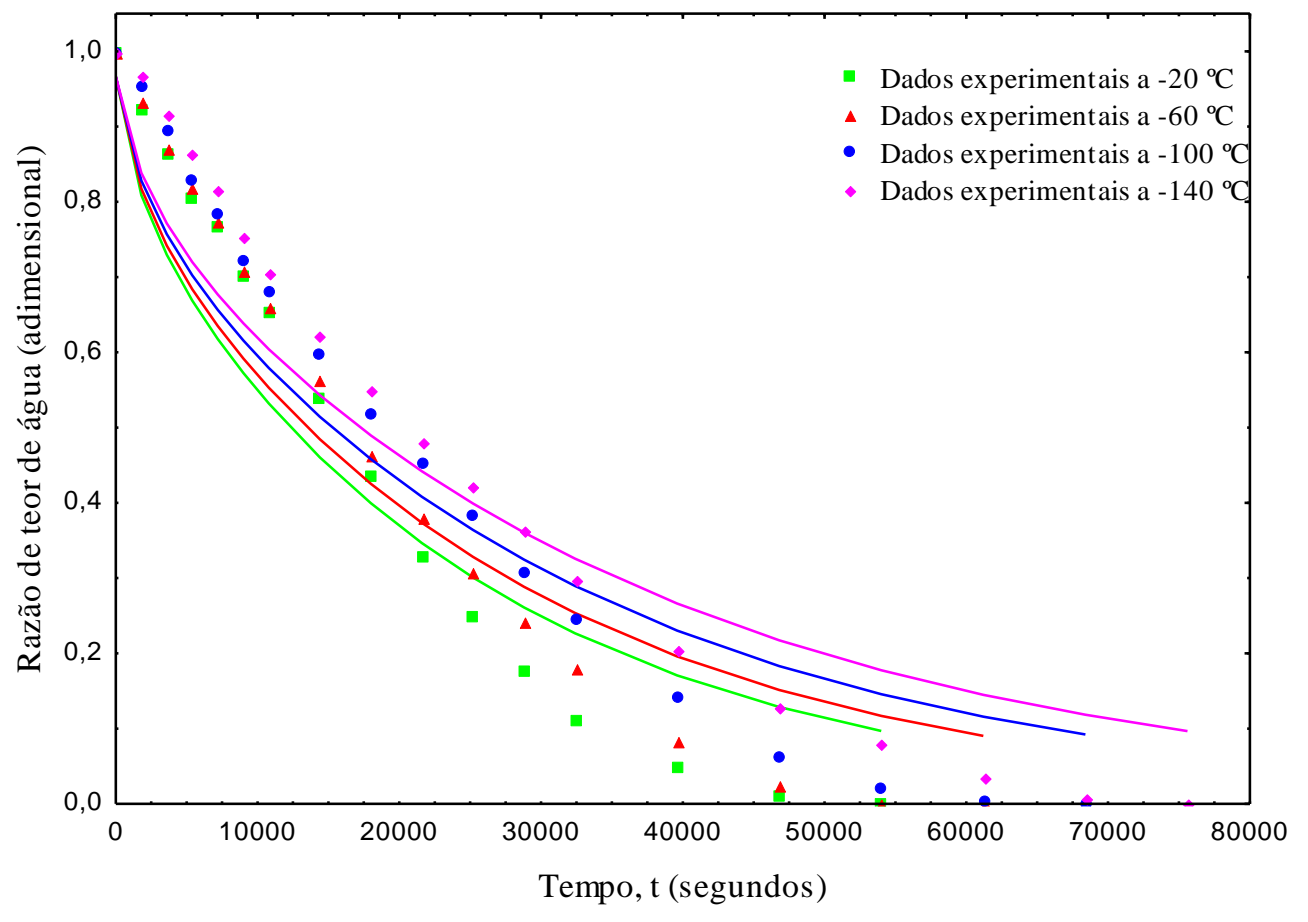

Fonte: Autores (2021).

Verifica-se, na Tabela 2, que o coeficiente de determinação ajustado $\left(\mathrm{R}_{\mathrm{a}}{ }^{2}\right)$ passou de $86 \%\left(1^{\circ}\right.$ termo) para $92 \%\left(6^{\circ}\right.$ termos), com o aumento de número de termos da série, deduzindo-se que com aumento dos termos da série aumenta-se a representatividade da equação obtendo-se um resultado mais realista do processo. 
Tabela 1. Parâmetros da cinética de secagem do leite asinino, por meio do modelo de Fick até o 6 termo da série, com seus respectivos coeficientes de determinação $\left(R^{2}\right)$, coeficientes de determinação ajustado $\left(R^{2}{ }_{\text {a }}\right)$ para as cinco temperaturas $\left(-20{ }^{\circ} \mathrm{C}\right.$, $\left.60{ }^{\circ} \mathrm{C},-100{ }^{\circ} \mathrm{Ce}-140{ }^{\circ} \mathrm{C}\right)$.

\section{Fick modificado}

\begin{tabular}{|c|c|c|c|c|c|c|}
\hline \multirow[b]{2}{*}{$\mathbf{T}\left({ }^{\circ} \mathbf{C}\right)$} & \multicolumn{3}{|c|}{1 Termo } & \multicolumn{3}{|c|}{2 Termos } \\
\hline & $\begin{array}{c}\text { Ds } \\
\left(10^{-10} \mathrm{~m}^{2} \mathrm{~s}^{-1}\right)\end{array}$ & $\mathbf{R}^{2}$ & $\mathbf{R}^{2}{ }_{a}$ & $\begin{array}{c}\text { Ds } \\
\left(10^{-10} \mathrm{~m}^{2} \mathrm{~s}^{-1}\right)\end{array}$ & $\mathbf{R}^{2}$ & $\mathbf{R}_{\mathrm{a}}^{2}$ \\
\hline-20 & 3,99 & 86,95 & 86,02 & 3,93 & 89,93 & 89,21 \\
\hline-60 & 3,57 & 88,23 & 87,44 & 3,60 & 91,24 & 90,66 \\
\hline-100 & 3,03 & 88,12 & 87,38 & 3,13 & 91,34 & 90,80 \\
\hline-140 & 3,02 & 88,06 & 87,36 & 2,72 & 91,55 & 91,05 \\
\hline \multirow[b]{2}{*}{$\mathbf{T}\left({ }^{\circ} \mathbf{C}\right)$} & \multicolumn{3}{|c|}{3 Termos } & \multicolumn{2}{|c|}{4 Termos } & \\
\hline & $\begin{array}{c}\text { Ds } \\
\left(10^{-10} \mathrm{~m}^{2} \mathrm{~s}^{-1}\right)\end{array}$ & $\mathbf{R}^{2}$ & $\mathbf{R}^{2}{ }_{a}$ & $\begin{array}{c}\text { Ds } \\
\left(10^{-10} \mathrm{~m}^{2} \mathrm{~s}^{-1}\right) \\
\end{array}$ & $\mathbf{R}^{2}$ & $\mathbf{R}_{\mathbf{a}}^{2}$ \\
\hline-20 & 3,91 & 90,31 & 89,62 & 3,95 & 90,43 & 89,75 \\
\hline-60 & 3,60 & 91,62 & 91,06 & 3,61 & 91,73 & 91,18 \\
\hline-100 & 3,20 & 91,79 & 91,28 & 3,19 & 91,90 & 91,39 \\
\hline \multirow[t]{2}{*}{-140} & 2,83 & 92,00 & 91,53 & 2,83 & 92,11 & 91,64 \\
\hline & \multicolumn{3}{|c|}{5 Termos } & \multicolumn{3}{|c|}{6 Termos } \\
\hline $\mathbf{T}\left({ }^{\circ} \mathbf{C}\right)$ & $\begin{array}{c}\text { Ds } \\
\left(10^{-10} \mathrm{~m}^{2} \mathrm{~s}^{-1}\right)\end{array}$ & $\mathbf{R}^{2}$ & $\mathbf{R}^{2} \mathbf{a}$ & $\begin{array}{c}\text { Ds } \\
\left(10^{-10} \mathrm{~m}^{2} \mathrm{~s}^{-1}\right)\end{array}$ & $\mathbf{R}^{2}$ & $\mathbf{R}_{\mathbf{a}}^{2}$ \\
\hline-20 & 3,95 & 90,48 & 89,80 & 3,95 & 90,51 & 89,83 \\
\hline-60 & 3,61 & 91,78 & 91,23 & 3,61 & 91,80 & 91,25 \\
\hline-100 & 3,19 & 91,94 & 91,44 & 3,19 & 91,97 & 91,47 \\
\hline-140 & 2,83 & 92,16 & 91,70 & 2,83 & 92,18 & 91,72 \\
\hline
\end{tabular}

Fonte: Autores (2021).

Pode-se observar, também, na Tabela 2, que embora ocorra o aumento dos coeficientes de determinação com o acréscimo do número de termos da série, a difusividade sublimação efetiva (Ds) quase não se altera, apenas constatando-se uma oscilação que tem pouca efetividade na ordem de grandeza dos valores. Analisa-se também neste trabalho, que quanto maior a temperatura de congelamento $\left(-20^{\circ} \mathrm{C}\right)$, maior o valor da difusividade e consequentemente, maior a velocidade de remoção das moléculas de água do produto. Crespi (2016) avaliando a difusividade efetiva para o modelo de Fick na cinética de liofilização de fatias de manga obteve valores variando entre $0,6094.10^{-8}$ e $2,1244.10^{-8} \mathrm{~m}^{2} / \mathrm{s}$ com coeficientes de determinação $\left(\mathrm{R}^{2}\right)$ superior a 95\%. Esses valores são superiores aos verificados no presente trabalho, porém deve-se considerar que os produtos são diferentes e, portanto, apresentam diferentes estruturas celulares e comportamentos durante o processamento, e, ainda, que as metodologias de secagem empregadas são distintas.

Nas Figuras 3, 4 e 5 encontram-se os dados experimentais da cinética de liofilização do leite asinino e os calculados respectivamente pelo Modelo de Cavalcanti-Mata modificado, Modelo de Lewis modificado e Modelo de Page modificado para as temperaturas de congelamento de $-20,-60,-100$ e $140^{\circ} \mathrm{C}$. 
Figura 3. Dados experimentais e calculados da secagem de liofilização do leite asinino nas temperaturas de congelamento -20 a $-140^{\circ} \mathrm{C}$, utilizando-se o Modelo de Cavalcanti-Mata modificado.

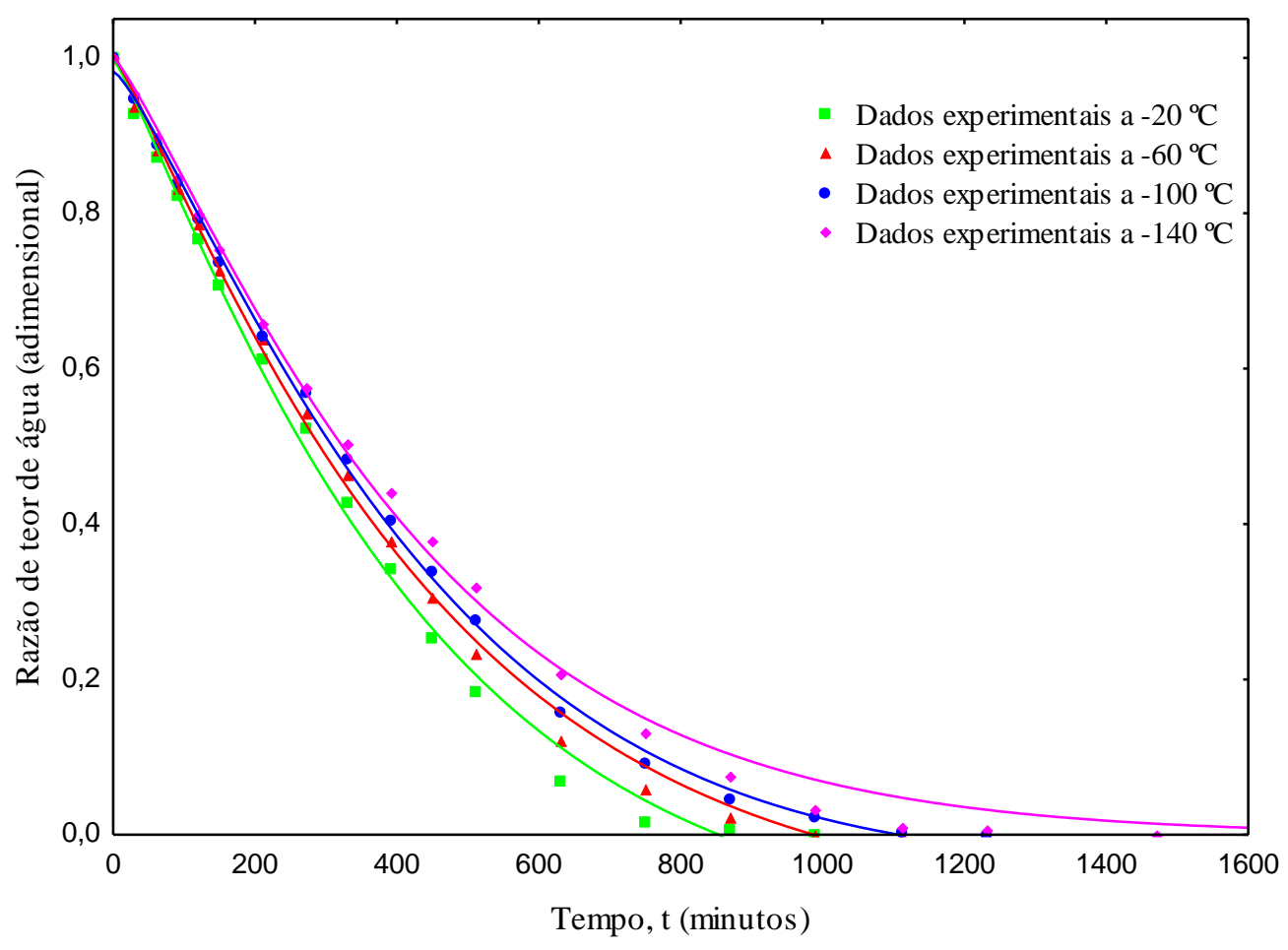

Fonte: Autores (2021).

Figura 4. Dados experimentais e calculados da secagem de liofilização do leite asinino nas temperaturas de congelamento $-20 \mathrm{a}-140^{\circ} \mathrm{C}$ utilizando-se o Modelo de Lewis modificado.

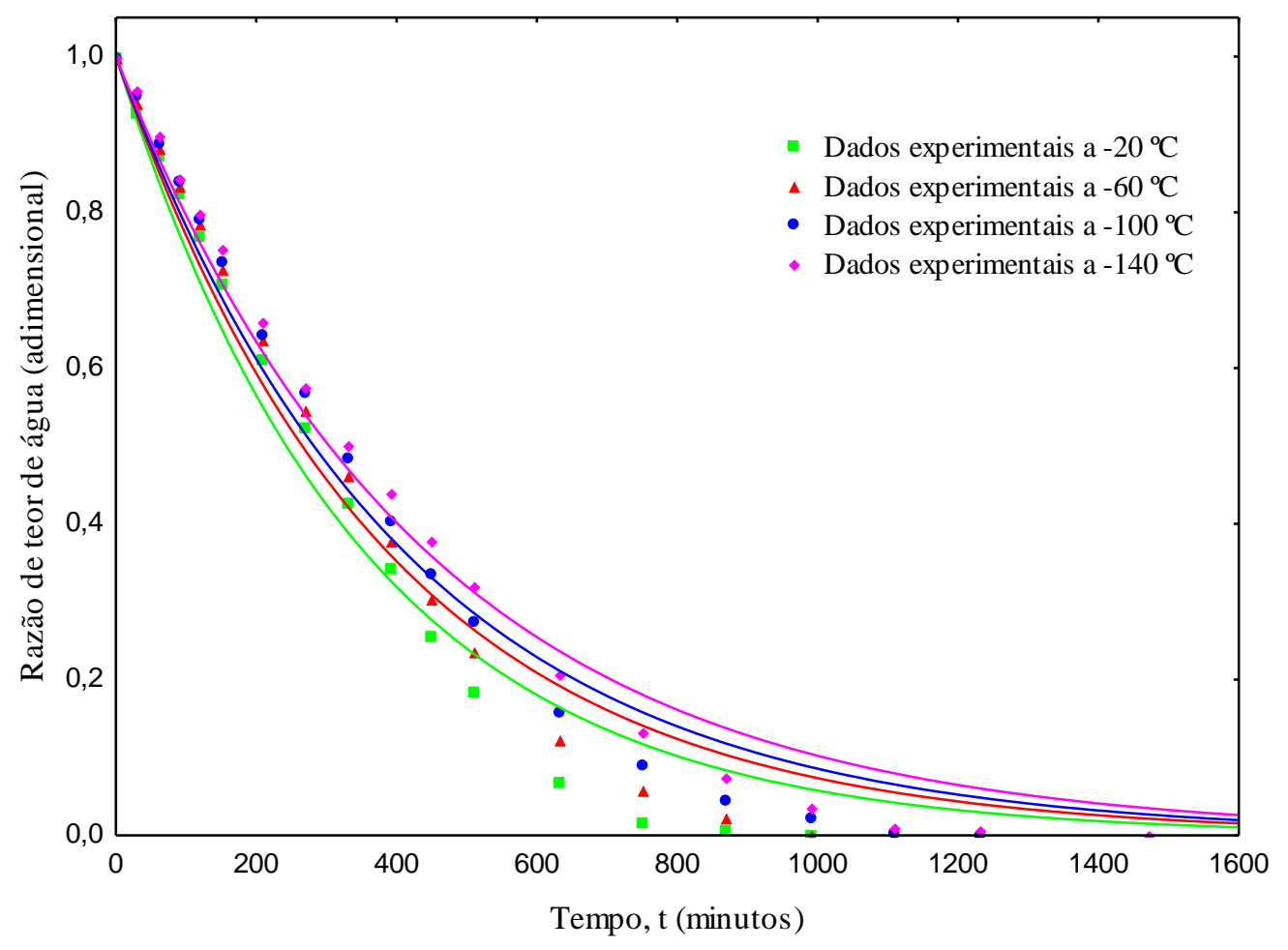

Fonte: Autores (2021). 
Figura 5. Dados experimentais e calculados da secagem de liofilização do leite asinino nas temperaturas de congelamento $-20 \mathrm{a}-140^{\circ} \mathrm{C}$ utilizando-se o Modelo de Page modificado.

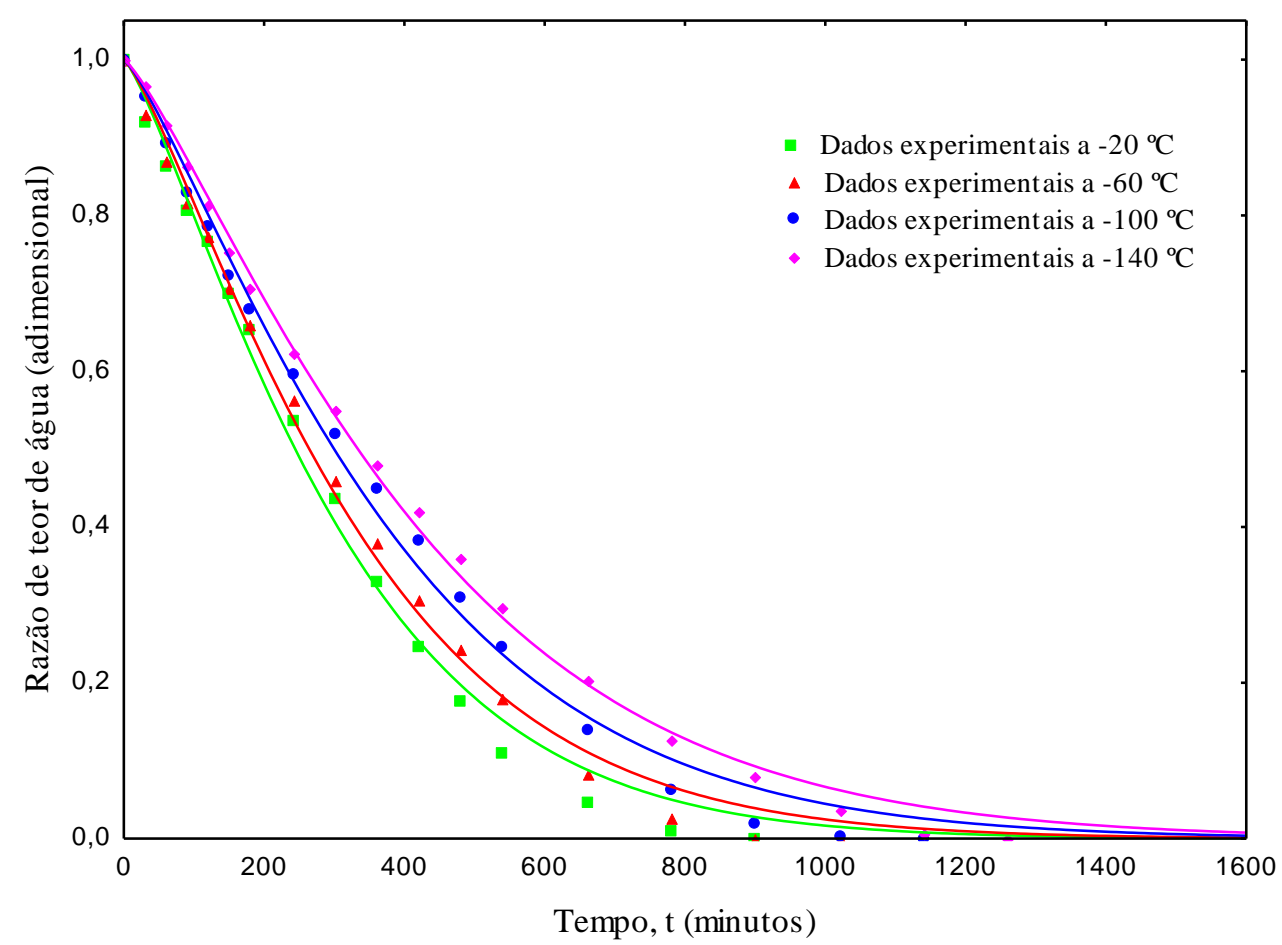

Fonte: Autores (2021).

Na Tabela 3 encontram-se, respectivamente os parâmetros referentes a esses modelos semiteóricos e semiempíricos, bem como os valores estatísticos que são os coeficientes de determinação $\left(R^{2}\right)$, coeficiente de determinação ajustado $\left(R^{2}{ }_{a}\right)$, erro médio relativo $(\mathrm{P})$, erro médio estimado (SE) e o desvio quadrático médio (DQM). 
Tabela 3. Parâmetros estimados dos modelos de Cavalcanti-Mata modificado, Lewis e Page modificados por Cavalcanti-Mata, da secagem de liofilização do leite asinino nas temperaturas de $-20{ }^{\circ} \mathrm{C},-60{ }^{\circ} \mathrm{C},-100{ }^{\circ} \mathrm{C}$ e $-140{ }^{\circ} \mathrm{C}$.

\begin{tabular}{|c|c|c|c|c|c|c|c|c|c|c|}
\hline \multicolumn{11}{|c|}{ Cavalcanti-Mata modificado } \\
\hline Temperatura & $\mathbf{a}_{1}$ & $\begin{array}{c}\text { Ds } \\
\left(10^{-12} \mathrm{~m}^{2} \mathrm{~s}^{-1}\right)\end{array}$ & $\mathbf{n}_{1}$ & $\mathbf{a}_{2}$ & $\mathbf{n}_{2}$ & $\begin{array}{l}\mathrm{R}^{2} \\
(\%)\end{array}$ & $\begin{array}{l}\mathbf{R}^{2} \mathrm{a} \\
(\%)\end{array}$ & $\begin{array}{c}\mathbf{P} \\
(\%)\end{array}$ & SE & DQM \\
\hline$-20^{\circ} \mathrm{C}$ & 1,1392 & 2,8334 & 1,1358 & $-0,1409$ & 0,5102 & 99,63 & 99,38 & 1,479 & 0,016 & 0,0060 \\
\hline$-60{ }^{\circ} \mathrm{C}$ & 1,0993 & 2,6667 & 1,1326 & $-0,0963$ & 0,0926 & 99,79 & 99,66 & 1,283 & 0,019 & 0,0022 \\
\hline$-100^{\circ} \mathrm{C}$ & 1,3884 & 2,1667 & 1,1595 & $-0,4059$ & 0,9194 & 99,90 & 99,84 & 0,283 & 0,006 & 0,0001 \\
\hline$-140^{\circ} \mathrm{C}$ & 0,9748 & 1,8334 & 1,2013 & 0,0255 & 1,0564 & 99,70 & 99,55 & 0,189 & 0,104 & 0,0080 \\
\hline
\end{tabular}

Lewis modificado por Cavalcanti-Mata

\begin{tabular}{ccccccc}
\hline Temperatura & $\begin{array}{c}\mathbf{D}_{\mathbf{s}} \\
\left(\mathbf{1 0}^{-\mathbf{1 2}} \mathbf{~}^{\mathbf{2}} \mathbf{s}^{-\mathbf{1}}\right)\end{array}$ & $\begin{array}{c}\mathbf{R}^{\mathbf{2}} \\
(\boldsymbol{\%})\end{array}$ & $\begin{array}{c}\mathbf{R}^{\mathbf{2}} \mathbf{a} \\
(\boldsymbol{\%})\end{array}$ & $\begin{array}{c}\mathbf{P} \\
(\boldsymbol{\%})\end{array}$ & $\mathbf{S E}$ & $\mathbf{D Q M}$ \\
\hline $\mathbf{- 2 0}{ }^{\circ} \mathrm{C}$ & 7,781 & 97,30 & 97,11 & 6,392 & 0,044 & 0,0077 \\
$\mathbf{- 6 0}{ }^{\circ} \mathrm{C}$ & 7,125 & 97,82 & 97,67 & 5,532 & 0,041 & 0,0066 \\
$\mathbf{- 1 0 0}{ }^{\circ} \mathrm{C}$ & 6,699 & 98,28 & 98,17 & 4,041 & 0,043 & 0,0076 \\
$\mathbf{- 1 4 0}{ }^{\circ} \mathrm{C}$ & 6,225 & 98,61 & 98,53 & 3,227 & 0,046 & 0,0020
\end{tabular}

Page modificado por Cavalcanti-Mata

\begin{tabular}{cccccccc}
\hline Temperatura & $\begin{array}{c}\mathbf{D s} \\
\left(\mathbf{1 0}^{-\mathbf{1 2}} \mathbf{m}^{\mathbf{2}} \mathbf{s}^{-\mathbf{1}}\right)\end{array}$ & $\mathbf{n}$ & $\begin{array}{c}\mathbf{R}^{\mathbf{2}} \\
(\boldsymbol{\%})\end{array}$ & $\begin{array}{c}\mathbf{R}_{\mathbf{a}}^{\mathbf{a}} \\
(\boldsymbol{\%})\end{array}$ & $\begin{array}{c}\mathbf{P} \\
(\boldsymbol{\%})\end{array}$ & $\mathbf{S E}$ & $\mathbf{D Q M}$ \\
\hline $\mathbf{- 2 0}{ }^{\circ} \mathrm{C}$ & 1,8337 & 1,2426 & 99,40 & 99,31 & 2,671 & 0,032 & 0,0320 \\
$\mathbf{- 6 0}{ }^{\circ} \mathrm{C}$ & 1,667 & 1,2455 & 99,59 & 99,53 & 0,612 & 0,089 & 0,0290 \\
$\mathbf{- 1 0 0}{ }^{\circ} \mathrm{C}$ & 1,5003 & 1,2599 & 99,45 & 99,38 & 1,015 & 0,095 & 0,0340 \\
$\mathbf{- 1 4 0}{ }^{\circ} \mathrm{C}$ & 1,3336 & 1,2601 & 99,75 & 99,72 & 1,400 & 0,237 & 0,0050 \\
\hline
\end{tabular}

Fonte: Autores (2021).

Constata-se na Tabela 3 que em todos os modelos semiteóricos e semiempíricos estudados a exemplo do que ocorre com o modelo Fick modificado a difusividade de sublimação efetiva $\left(D_{S}\right)$ decresce com a diminuição da temperatura de congelamento. Contudo, observa-se que no Modelo de Cavalcanti-Mata modificado os parâmetros $\mathrm{a}_{1}, \mathrm{n}_{1}, \mathrm{a}_{2}, \mathrm{n}_{2}$, não apresentam uma tendência em função da diminuição da temperatura, entendendo que estes valores estão mais relacionados aos ajustes matemáticos do que com os fenômenos de secagem. No Modelo de Page modificado, o parâmetro "n" aumentou a medida que a temperatura decresceu, representando assim segundo os autores Mendonça et al. (2015), que o parâmetro "n" da equação de Page, possui um efeito de moderação no tempo de secagem, corrigindo os prováveis erros de negligência da resistência interna ao transporte de água.

Na Tabela 3 temos ainda que, para as temperaturas de congelamento de -20 a $-140^{\circ} \mathrm{C}$ os valores da difusividade de sublimação efetiva (Ds) variaram de 2,83.10 $10^{-12} \mathrm{~m}^{2} \mathrm{~s}^{-1}$ a $1,83 \cdot 10^{-12} \mathrm{~m}^{2} \mathrm{~s}^{-1}$ para o modelo de Cavalcanti-Mata modificado, de 7,78. $10^{-12} \mathrm{~m}^{2} \mathrm{~s}^{-1}$ a $6,22.10^{-12} \mathrm{~m}^{2} \mathrm{~s}^{-1}$ para o modelo de Lewis modificado e de $1,83 \cdot 10^{-12} \mathrm{~m}^{2} \mathrm{~s}^{-1}$ a $1,33.10^{-12} \mathrm{~m}^{2} \mathrm{~s}^{-1}$ para o modelo de Page modificado, evidenciando que quanto mais baixa a temperatura de congelamento mais difícil ocorreu a remoção de água do leite asinino durante o processo de liofilização. Oliveira (2016) observou comportamento semelhante ao estudar o coeficiente de 
sublimação (difusividade de sublimação efetiva) na cinética de liofilização para polpa de maracujá do mato in natura (FC) em diferentes temperaturas de congelamento $\left(-25,-60,76 \mathrm{e}-170{ }^{\circ} \mathrm{C}\right)$.

Analisando os valores médios do coeficiente de sublimação (difusividade de sublimação efetiva) para polpa de maracujá do mato in natura (FC), Oliveira (2016) obteve resultados variando de $1,92.10^{-9} \mathrm{~m}^{2} \mathrm{~s}^{-1}$ a $1,42.10^{-9} \mathrm{~m}^{2} \mathrm{~s}^{-1}$, valores bem superiores aos encontrados no presente trabalho para o leite asinino que apresentou casa decimal da ordem de $10^{-12} \mathrm{~m}^{2} \cdot \mathrm{s}^{-1}$, entretanto podese justificar este fato relacionado às diferenças estruturais de cada produto e ao próprio processo de liofilização realizado nos dois trabalhos.

Na Figura 6 encontram-se os dados experimentais e calculados da cinética de liofilização do leite de asinino obtido pelo modelo empírico de Midilli e de seus colaboradores para as temperaturas de congelamento -20 a $-140^{\circ} \mathrm{C}$, e na Tabela 4 , encontram-se os parâmetros referentes a esse modelo de Midilli, constando também, os valores estatísticos dos coeficientes de determinação $\left(R^{2}\right)$, coeficiente de determinação ajustado $\left(R^{2}{ }^{2}\right)$, erro médio relativo $(P)$, erro médio estimado (SE) e o desvio quadrático médio (DQM).

Observando a Tabela 4, nota-se que os parâmetros para o modelo de Midilli et al. apresentaram conduta semelhante aos modelos que se encontram na Tabela 3, e nesta tabela se evidencia que a constante de sublimação (Ks) tem o mesmo comportamento da difusividade efetiva (Ds), diminuindo conforme a temperatura decresce. Este fato também foi observado por Oliveira (2016) ao analisar os valores da constante de sublimação para o modelo de Midilli et al. na cinética de liofilização para polpa de maracujá do mato in natura (FC) em diferentes temperaturas de congelamento $\left(-25,-60,76\right.$ e $\left.-170{ }^{\circ} \mathrm{C}\right)$.

Figura 6. Dados experimentais e calculados da secagem de liofilização do leite asinino nas temperaturas de congelamento -20 a $-140^{\circ} \mathrm{C}$ utilizando-se o Modelo de Midilli et al.

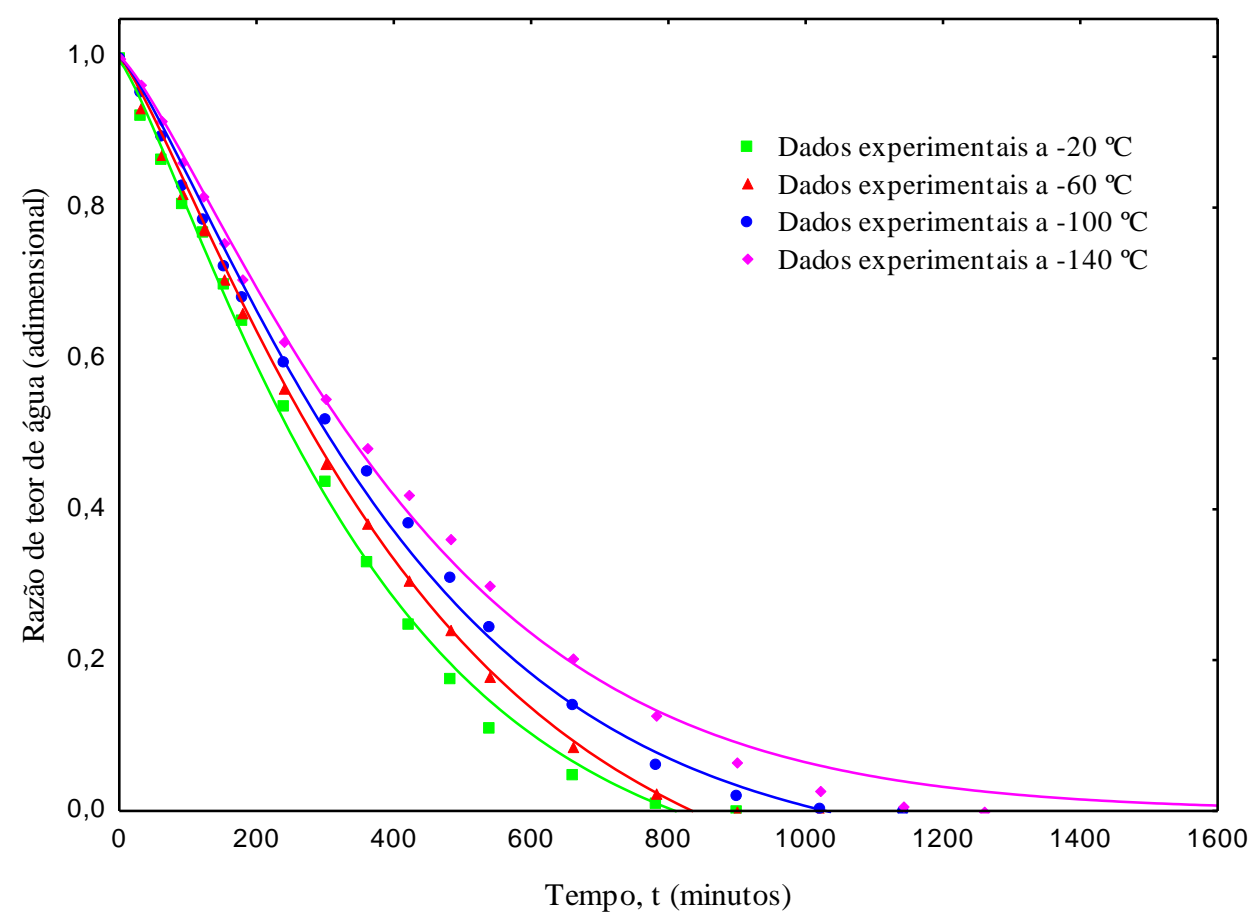

Fonte: Autores (2021). 
Tabela 4. Parâmetros estimados do modelo de Midilli et al. da secagem de liofilização do leite asinino nas temperaturas de $-20{ }^{\circ} \mathrm{C},-60{ }^{\circ} \mathrm{C},-100{ }^{\circ} \mathrm{C} \mathrm{e}-140{ }^{\circ} \mathrm{C}$.

\begin{tabular}{|c|c|c|c|c|c|c|c|c|c|}
\hline $\begin{array}{c}\text { Midilli } \\
\text { et al. }\end{array}$ & $\mathbf{a}$ & $\begin{array}{c}\mathrm{Ks} \\
\left(\mathrm{mm}^{2} / \mathrm{min}\right)\end{array}$ & $\mathbf{n}$ & $\mathbf{b}$ & $\mathbf{R}^{2}(\%)$ & $\begin{array}{c}\mathbf{R}^{2} \mathbf{a} \\
(\%) \\
\end{array}$ & $\mathbf{P}(\%)$ & SE & DQM \\
\hline$-20^{\circ} \mathrm{C}$ & 0,995 & 0,00077 & 1,219 & $-0,000081$ & 99,70 & 99,65 & 2,099 & 0,034 & 0,007 \\
\hline$-60^{\circ} \mathrm{C}$ & 1,000 & 0,00065 & 1,220 & $-0,000108$ & 99,54 & 99,47 & 1,144 & 0,081 & 0,021 \\
\hline$-100^{\circ} \mathrm{C}$ & 1,000 & 0,00053 & 1,250 & $-0,000045$ & 99,66 & 99,61 & 1,478 & 0,108 & 0,004 \\
\hline$-140^{\circ} \mathrm{C}$ & 1,000 & 0,00040 & 1,270 & $-0,000042$ & 99,40 & 99,32 & 3,591 & 0,227 & 0,176 \\
\hline
\end{tabular}

Fonte: Autores (2021).

Analisando os modelos estudados (Tabelas 3 e 4), os coeficientes de determinação ajustados $\left(R_{a}{ }^{2}\right)$ ficaram acima de 97,11\%; P abaixo de 6,4, SE e DQM abaixo de 0,227 e 0,176, respectivamente, demonstrando que os modelos tiveram ajustes satisfatórios aos dados obtidos experimentalmente. Entretanto, para determinar qual dos modelos estudados apresentou o melhor ajuste aos dados experimentais, é necessário analisar outros parâmetros estatísticos. Desta forma, de acordo com Madamba, et al. (1996) pode-se utilizar os valores do erro médio relativo (P) e erro médio estimado (SE). Nestes casos os dados de DQM também podem ser considerados como critérios complementares de avaliação (Martins et al.,2014).

Segundo Mohapatra \& Rao (2005), a magnitude desse erro relativo (P) deve ser inferior a 10\%, sinalizando que esta equação descreve melhor o processo de secagem do que outra. Já o uso do erro médio estimado (SE) é interessante por medir o erro cometido pelo modelo na mesma unidade física da variável estimada (Botelho et al., 2018). Fazendo-se uma análise completa para todos os modelos matemáticos, nota-se que o modelo de Cavalcanti-Mata modificado foi o que apresentou para a cinética secagem por liofilização do leite asinino, os melhores valores obtendo-se coeficientes de determinação ajustados $\left(R_{\mathrm{a}}{ }^{2}\right)$ acima de 99,38 \%, P abaixo de 1,479, SE e DQM abaixo de 0,104 e 0,0022, respectivamente. Ferreira (2011) estudando os modelos matemáticos na cinética de liofilização no desenvolvimento da umbuzada em pó, também percebeu que o modelo de CavalcantiMata apresentou os melhores ajustes aos seus dados experimentais. De acordo com Celma et al., (2009), os resultados da difusividade efetiva e demais informações obtidas pela modelagem matemática das curvas de secagem, são dados essenciais para o desenvolvimento, construção e aprimoramento de equipamentos de secagem. Considera-se ainda, que a difusividade efetiva é um importante valor no fenômeno de transporte, sendo muito útil na análise dos processos de processamento dos produtos, como a secagem.

A conformidade do coeficiente de difusividade de sublimação efetiva $\left(\mathrm{D}_{\mathrm{s}}\right)$ do leite de asinino em função da temperatura de congelamento pode ser corretamente representada pela expressão de Arrhenius. Sendo assim, através da referida expressão foram plotados os valores do logaritmo neperiano dos coeficientes da difusividade efetiva [ln (Ds)] em função do inverso da temperatura absoluta, obtendo-se, em sequência, o coeficiente angular de cada reta que corresponde à relação $E / R$, para cada faixa de temperatura segundo ilustrado na Figura 7. Portanto, ao multiplicar-se o valor do coeficiente angular da reta por 8,314 adquire-se o valor da energia de ativação para cada faixa de temperatura. 
Figura 7. Representação de Arrhenius para a difusividade efetiva em função da temperatura de congelamento estimada pelos modelos de Fick modificado, Lewis modificado, Cavalcanti-Mata modificado e Page modificado.

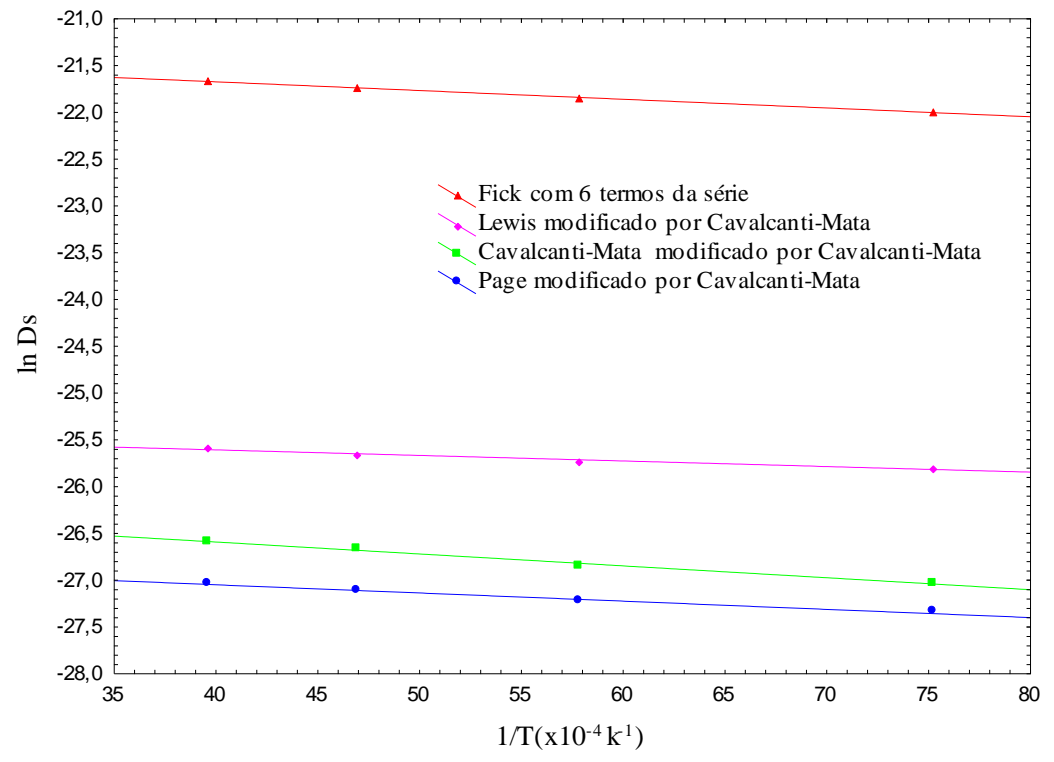

Fonte: Autores (2021).

Na Tabela 5 são apresentados os valores da energia de ativação do leite asinino para os modelos das difusividades analisadas. Como pode ser observada, para a energia de ativação encontraram-se valores de 0,795 kJ mol-1 para o modelo Fick, $1,074 \mathrm{~kJ} \mathrm{~mol}^{-1}$ para o modelo Cavalcanti Mata modificado, $0,509 \mathrm{~kJ} \mathrm{~mol}^{-1}$ para o modelo Lewis modificado e $0,748 \mathrm{~kJ} \mathrm{~mol}^{-1}$ para o modelo Page modificado.

Tabela 5. Valores da energia de ativação para o leite asinino em diferentes modelos matemáticos nas temperaturas de congelamento de $-20{ }^{\circ} \mathrm{C},-60{ }^{\circ} \mathrm{C},-100{ }^{\circ} \mathrm{C}$ e $-140{ }^{\circ} \mathrm{C}$.

\begin{tabular}{cc}
\hline Modelos & Energia de ativação (kJ $\left.\mathbf{~ m o l}^{\mathbf{- 1}}\right)$ \\
\hline Fick & 0,795 \\
Cavalcanti-Mata & 1,074 \\
Lewis & 0,509 \\
Page & 0,748 \\
\hline
\end{tabular}

Fonte: Autores (2021).

A energia de ativação decorrente do processo de secagem por liofilização do leite asinino é inferior ao obtidos por outros autores, contudo na mesma ordem de grandeza como é ocaso da energia de ativação obtida de $2,12 \mathrm{~kJ}^{\text {mol }}{ }^{-1}$ por Oliveira et al. (2015) na secagem de morango. Este resultado indica que a secagem por liofilização do leite de asinino ocorreu com maior facilidade que a secagem de morangos, apresentado uma coerência entre as diferentes estruturas (líquido, semissólido) e temperaturas e processos. De acordo com Corrêa et al. (2017) quanto menor a energia de ativação, mais facilmente ocorre um processo específico, ou seja, menor a energia necessária para o processamento físico. A energia de ativação que é a medida da energia necessária para iniciar a difusão de água no interior do alimento, indica a sensibilidade do coeficiente de difusão efetivo à temperatura de secagem, sendo um apontador útil na avaliação do consumo total de energia no processo de secagem (Olanipekun et al., 2015) 
Com as informações da energia de ativação, foram determinadas as propriedades termodinâmicas: entalpia, entropia e energia livre de Gibbs, relativas aos processos de secagem por liofilização do leite asinino para os modelos estudados à diferentes temperaturas de congelamento $\left(-20,-60,-100\right.$ e $\left.-140{ }^{\circ} \mathrm{C}\right)$, Tabela 6 .

Tabela 6. Propriedades termodinâmicas para diferentes modelos matemáticos de secagem por liofilização do leite de asinino congelado as temperaturas de $-20{ }^{\circ} \mathrm{C},-60{ }^{\circ} \mathrm{C},-100{ }^{\circ} \mathrm{Ce}-140{ }^{\circ} \mathrm{C}$.

\begin{tabular}{|c|c|c|c|c|}
\hline Modelos & $\begin{array}{l}\mathbf{T} \\
{ }^{\circ} \mathbf{C}\end{array}$ & $\begin{array}{c}(\Delta \mathrm{H}) \\
\mathrm{J} \mathrm{mol}^{-1}\end{array}$ & $\begin{array}{c}(\Delta S) \\
J_{~ m o l^{-1}} K^{-1}\end{array}$ & $\begin{array}{c}(\Delta \mathbf{G}) \\
\mathrm{J} \mathrm{mol}^{-1}\end{array}$ \\
\hline \multirow{4}{*}{$\begin{array}{c}\text { Fick } \\
\text { modificado }\end{array}$} & -20 & $-1308,84$ & $-229,09$ & 56650,19 \\
\hline & -60 & $-976,28$ & $-227,66$ & 47514,50 \\
\hline & -100 & $-643,72$ & $-225,93$ & 38441,64 \\
\hline & -140 & $-311,16$ & $-223,74$ & 29446,37 \\
\hline \multirow{4}{*}{$\begin{array}{l}\text { Cavalcanti-Mata } \\
\text { modificado }\end{array}$} & -20 & $-1029,41$ & $-230,58$ & 57306,99 \\
\hline & -60 & $-696,85$ & $-229,15$ & 48111,64 \\
\hline & -100 & $-364,29$ & $-227,42$ & 38979,11 \\
\hline & -140 & $-301,73$ & $-225,23$ & 29924,18 \\
\hline \multirow{4}{*}{$\begin{array}{c}\text { Lewis } \\
\text { modificado }\end{array}$} & -20 & $-1594,81$ & $-224,65$ & 55241,87 \\
\hline & -60 & $-1262,25$ & $-223,22$ & 46283,63 \\
\hline & -100 & $-929,69$ & $-221,490$ & 37388,21 \\
\hline & -140 & $-597,13$ & $-219,30$ & 28570,39 \\
\hline \multirow{4}{*}{$\begin{array}{c}\text { Page } \\
\text { modificado }\end{array}$} & -20 & $-1354,90$ & $-235,67$ & 58270,18 \\
\hline & -60 & $-1022,34$ & $-234,24$ & 48871,09 \\
\hline & -100 & $-689,78$ & $-232,51$ & 39534,82 \\
\hline & -140 & $-357,22$ & $-230,33$ & 30276,14 \\
\hline
\end{tabular}

Fonte: Autores (2021).

Analisando todos os modelos na Tabela 6, observa-se que a entalpia apresentou valores negativos e aumentou com a diminuição da temperatura de congelamento. De acordo com Oliveira et al. (2015) os valores negativos de variação de entalpia representam uma transformação exotérmica, ou seja, processo com liberação de calor. Portanto, menores valores de variação de entalpia indicam menor energia necessária para remover a água ligada ao produto durante a secagem (Oliveira et al., 2010), desta forma, este estudo mostrou-se como esperado, pois apresentou menores valores de entalpia em temperaturas de secagem mais elevadas $\left(-20^{\circ} \mathrm{C}\right)$, indicando que menos energia é necessária para remover a água ligada ao produto durante a secagem.

Observando o comportamento da entropia nos modelos, analisa-se que essa propriedade termodinâmica tiveram um desempenho similar à entalpia na qual os valores foram negativos e cresceram enquanto a temperatura de congelamento diminuía. Segundo Corrêa et al. (2017) a Entropia é uma quantidade termodinâmica associada ao grau de desordem, pois é uma função de estado em que os valores aumentam durante um processo natural em um sistema isolado. Sendo assim, a temperatura de congelamento de $-20^{\circ} \mathrm{C}$ com formação de cristais de gelo maiores, pois se trata de um congelamento lento, foi a que demostrou o menor grau de desordem para a secagem de liofilização do leite de asinino.

Com relação a energia livre de Gibbs, nota-se que ocorreu uma redução com a temperatura de congelamento, apresentando valores positivos para toda faixa de temperatura estudada, indicando que a secagem nas condições atuais do estudo não foram 
espontâneas. O valor positivo da energia livre de Gibbs é característico de uma reação endergônica, em que requer uma adição de energia proveniente do meio em que o produto está envolvido para que ocorra a reação (Araújo et al., 2017).

\section{Conclusão}

O estudo sobre a secagem de liofilização do leite asinino demonstrou que com a diminuição da temperatura de congelamento ocorreu o aumento do tempo de secagem. Dentre os modelos estudados para a cinética de secagem de liofilização, o modelo de Cavalcanti-Mata foi o que apresentou o melhore ajuste aos dados experimentais para o leite de asinino, tendo coeficientes de determinação ajustado $\left(\mathrm{R}^{2}\right.$ ) superiores a $99,38 \%$, valores baixos de $\mathrm{SE}$, DQM e magnitudes do erro médio relativo (P) inferior a 10\%, indicando que o modelo pode ser utilizado na descrever este processo de liofilização. Em todos os modelos estudados (Fick modificado, Cavalcanti-Mata modificado, Lewis modificado e Page modificado), a difusividade efetiva decresce com a diminuição da temperatura do produto congelado durante o processo de liofilização. A entalpia e entropia cresce à medida que a temperatura do produto congelado diminuiu e a energia livre de Gibbs foi positiva para toda a faixa de temperatura, demonstrando assim, ser um processo não espontâneo.

Como sugestão para trabalhos futuros, poderão ser realizadas análises para caracterização físico-química e física do leite asinino em pós obtido na liofilização, a fim de determinar sua composição nutricional e qualidade quanto a padronização de granulometria, molhabilidade, solubilidade e higroscopicidade.

\section{Referências}

Araújo, W. D., Goneli, A. L. D., Corrêa, P. C., Hartmann Filho, C. P. \& Siqueira, E. A. M. (2017). Modelagem matemática da secagem dos frutos de amendoim em camada. Revista Ciência Agronômica, 48 (03), 448-57.

Altomonte, I., Salari, F., Licitra, R. \& Martini, M. (2019). Donkey and human milk: insights into their compositional similarities: Insights into their compositional similarities. International Dairy Journal, 89, 111-8.

Botelho, F. M., Hauth M. R., Hoscher, R. H. \& Botelho, S. C. C. (2018). Modelagem matemática da contração volumétrica de grãos de soja durante o processo de secagem. Revista Engenharia na Agricultura, Viçosa, 26 (01), 1-12.

Carroccio, A., Cavataio, F., Montalto, GD., D’Amico, D., Alabrese, L. \& Iacono G. (2000). Intolerance to hydrolysed cow’s milk proteins in infants: clinical characteristics and dietary treatment. Clin Exp Allergy, 30(11),1597-603.

Celma, A. R., López-rodriguéz, F. \& Blázquez, C. (2009). Experimental modelling of infrared drying of industrial grape by-products. Food and Bioproducts Processing, 87, 247-253.

Corrêa, P. C., Oliveira, G. H. H., Oliveira, A. P. L. R., Botelho, F. M. \& Goneli, A. L. D. (2017). Propriedades termodinâmicas do processo de secagem e absorção de água de grãos de arroz. CyTA-Journal of Food, 15, 204-210.

Cosentino, C., Paolino, R., Freschi, P. \& Calluso, A. M. (2012). Short communication: jenny milk production and qualitative characteristics. J Dairy Sci, 95(6), $2910-5$.

Cosentino, C., Paolino, R., Musto, M. \& Freschi, P. (2015). Innovative Use of Jenny Milk from Sustainable Rearing. In: Vastola A (Ed). The Sustainability of Agro-Food and Natural Resource Systems in the Mediterranean Basin. Springer Open, 1, 113-32.

Crank, J. (1975). The mathematics of diffusion. Oxford: Clarendon Press, (2), 1975, 414.

Crespi, M. M. (2016). Cinética de liofilização de fatias de manga. Trabalho de conclusão de curso, Universidade Tecnológica Federal do Paraná. Medianeira, Paraná, Brasil.

FAO. Food and Agriculture Organization, United Nations, Rome. (2016). <http://www.fao.org/faostat/en/\#data/QA>.

Ferreira, J. C. (2011). Processo para desenvolvimento da umbuzada em pó liofilizada, comporta de polpa de umbu, extrato de soja e rapadura. Tese de Doutorado, Universidade Federal de Campina Grande, Campina Grande, Paraíba, Brasil.

Horn, M. M., Martins, V. C. A. \& Plepis, A. M. de G. (2010). Determinação da energia de ativação em hidrogéis poliméricos a partir de dados termogravimétricos. Polímeros, 20, 201-204.

Iacono, G., Carroccio, A., Cavataio, F., Montalto, G., Soresi, M. \& Balsamo V. (1992). Use of ass' milk in multiple food allergy. J Pediatr Gastroenterol Nutr,14(2), 81-177.

Jidean, V. A. \& Mpotokwana, S. M. (2009). Modeling of water absorption of botswana bambara varieties using Peleg's equation. Journal of Food Engineering, $92,182-188$. 
Machado, F. M. C. R. R. (2015). Projeto para Implementação de Uma Exploração de Asininos (Equus asinus) com o objetivo de Produzir Leite de Burra. Dissertação de Mestrado, Universidade de Lisboa, Lisboa, Portugual.

Madamba, P. S., Driscoll, R. H. \& Buckle, K. A. (1996). Thin-layer drying characteristics of garlic slices. Journal of Food Engineering. 29 (1), $75-97$.

Martins, J. J. A., Marques, J. I., Santos, D. C. \& Rocha, A. P. T. (2014). Modelagem matemática da secagem de cascas de mulungu. Biosci. J., 30 (6), 16521660 .

Martins, R. C. \& Jesus Júnior, A. L. (2011). Evolução da produção de coco no Brasil e o comércio internacional - Panorama 2010. Embrapa, (1), 32.

Massouras, T., Triantaphyllopoulos, K.A. \& Theodossiou, I. (2017). Chemical composition, protein fraction and fatty acid profile of donkey milk during lactation. International Dairy Journal, 75, 83-90.

Mendonça, A. P., Sampaio, P. T. B., Almeida, F. A. C., Ferreira, R. F. \& Novais, J. M. (2015). Determinação das curvas de secagem das sementes de andiroba em secador solar. R. Bras. Eng. Agríc. Ambiental, 19 (4), 382-387.

Mohapatra, D. \& Rao, P. S. (2005). A thin layer drying model of parboiled wheat. Journal of Food Engineering, 66 (4), $513-518$.

Olanipekun, B. F., Tunde-Akintunde, T. Y., Oyelade, O. J., Adebisi, M. G. \& \& Adenaya, T. A. (2015). Mathematical modeling of thin-layer pineapple drying. Journal of Food Processing and Preservation, 39(6), 1431-1441.

Oliveira, G. H. H., Aragão, D. M. S., Oliveira, A. P. L. R., SILVA, M. G. \& Gusmão, A. C. A. (2015). Modelagem e propriedades termodinâmicas na secagem de morangos. Brazilian Journal Of Food Research, 18 (4).

Oliveira, G. H. H., Corrêa, P. C., Araújo, E. F., Valente, D. S. M. \& Botelho, F. M. (2010). Desorption isotherms and thermodynamic properties of sweet corn cultivars (Zea mays L.). International Journal of Food Science and Technology, Londres, 45 (3), 546-554.

Oliveira, S. N. (2016). Liofilização de polpa de maracujá do mato (passiflora cincinnata mast.) para obtenção de produtos alimentícios. Tese (Doutorado em Engenharia Agrícola). Universidade Federal de Campina Grande. Campina Grande, Paraíba, Brasil.

Pereira A. S. et al. (2018). Metodologia da pesquisa científica. UFSM.

Rangel, A. H.N., Júnior, J. G. B. G., Simplício, A. A., Freire, R. M. B. \& Novaes, L. P. (2015). Aspectos composicionais e nutricionais do leite de jumenta: uma revisão. Revista do Instituto de Laticínios Cândido Tostes, 70(3), 160-171.

Salimei, E., \& Fantuz, F. (2012). Equid Milk for Human Consumption. International Dairy Journal, 24, $130-142$.

Santos, I. C. B. (2017). Produção e composição do leite de jumentas da raça pêga. Dissertação de mestrado, Universidade Federal da Bahia, Salvador, Bahia, Brasil.

SBP. Departamento Científico de Alergia da SBP lança documento inédito: Um Guia Prático Atualizado sobre anafilaxia. (2016). $<$ https://www.sbp.com.br/imprensa/detalhe/nid/departamento-cientifico-de-alergia-da-sbp-lanca-documento-inedito-um-guia-pratico-atualizado-sobreanafilaxia/>.

SILVA, R. F. (2015). Efeitos clínicos da infusão contínua de xilazina ou detomidina em asininos nordestinos pré-medicados ou não com hioscina. Trabalho de conclusão de curso, Universidade Federal da Paraíba. Areia, Paraíba, Brasil.

Trinchese, G., Cavaliere, G., Canani, R. B., Matamoros, S., Bergamo, P., De Filippo, C., et al. (2015). Human, donkey and cow milk differently affects energy efficiency and inflammatory state by modulating mitochondrial function and gut microbiota. J Nutr Biochem, 26(11), 1136-46. 